\title{
Treino Orientado à Tarefa na Doença de Charcot-Marie-Tooth do Tipo II - Estudo de Caso
}

\author{
Task Oriented Training in Charcot-Marie-Tooth Disease Type II - Case Report
}

\section{Tatiane Bratti ${ }^{1}$, Pablo Tortato Waltrick ${ }^{2}$}

\begin{abstract}
RESUMO
A Doença de Charcot-Marie-Tooth ocorre em cerca de uma a cada 2500 pessoas e se caracteriza pela degeneração da parte distal dos nervos motores e sensitivos. É classificada de acordo com a parte do nervo que é afetada e subclassificada conforme o gene que a causa. Tratou-se uma paciente com o tipo II, caracterizado pela perda axonal do nervo e maior comprometimento dos membros inferiores. A intervenção fisioterapêutica foi composta de 32 atendimentos. Avaliou-se o efeito da mesma sobre o tônus, o equilíbrio e a independência da marcha bem como sua permanência ou não após a fisioterapia. A paciente apresentou espasticidade, o que é pouco comum. Além disso, déficit de equilíbrio estático e dinâmico e uma marcha dificultada pela incapacidade de levantar o antepé, como o descrito na literatura. Observou-se melhora no equilíbrio estático e dinâmico, visualizada através da realização do teste de Berg bem como na mobilidade funcional e risco de quedas, verificados através do Teste do Tempo de Levantar e Andar antes e após o tratamento. Houve diminuição da incidência das quedas influenciada pelo trabalho de alongamento, que diminuiu a espasticidade, e pelo treino de equilíbrio estático e dinâmico responsável pela melhora da mobilidade funcional da paciente.
\end{abstract}

Unitermos. Doença de Charcot-Marie-Tooth, Fisioterapia, Exercícios de Alongamento Muscular, Equilíbrio Postural, Marcha. Citação. Bratti T, Waltrick PT. Treino Orientado à Tarefa na Doença de Charcot-Marie-Tooth do Tipo II - Estudo de Caso.

Trabalho realizado no Centro de Ciências da Saúde e do Esporte - Universidade do Estado de Santa Catarina - UDESC, Florianópolis -SC, Brasil.

1.Acadêmica do Curso de Fisioterapia do Centro de Ciências da Saúde e do Esporte, Universidade do Estado de Santa Catarina, UDESC, Florianópolis-SC, Brasil.

2.Orientador, Mestre em Neurociências, Professor da Faculdade

Estácio de Sá de Santa Catarina, Florianópolis -SC, Brasil.

\section{SUMMARY}

The Charcot-Marie-Tooth Disease occurs in about 1/2500 people and it is characterized by degeneration of the distal part of motor and sensitive nerves. It is classified according the affected part of the nerve in type I and II, and it is also sub classified following the causing gene. A female patient with type II, characterized by axonal degeneration and predominant involvement of lower limbs, was treated during 32 physiotherapy sessions. The effect of this treatment in its tonus, balance, functional mobility, and risk of falling was evaluated, checking if they are still there after physiotherapy. The patient had spasticity, which is not usual. She also had static and dynamic balance deficit, and her gait was more difficult because she can't lift her foot, like described by some authors. She has increased her static and dynamic balance, through Berg test, and she has increased her functional mobility, through Timed Up \& Go Test before and after physiotherapy. She also fell down less than before. The results had been influenced by stretching (which decreased the spasticity) and static and dynamic balance training, which made her functional mobility better.

Keywords. Charcot-Marie-Tooth Disease, Physical Therapy, Muscle Stretching Exercises, Postural Balance, Gait.

Citation. Bratti T, Waltrick PT. Task Oriented Training in Charcot-Marie-Tooth Disease Type II - Case Report
Relato de Caso

Recebido em: 18/12/2007

Revisado em: 19/12/2007 a 20/08/2008

Aceito em: 21/08/2008

Conflito de interesses: não

Endereço para correspondência: Tatiane Bratti

Av. Desembargador Pedro Silva, 2745/401

CEP 88080-701, Florianópolis-SC. e-mail: tatibratti@gmail.com 


\section{INTRODUÇÃO}

A Doença de Charcot-Marie-Tooth (CMT) foi descrita pela primeira vez em 1886 por Jean-Martin-Charcot e Pierre Marie na França e Howard Tooth na Inglaterra, mas somente no início da década de noventa é que se descobriu sua causa genéti$\mathrm{ca}^{1,2}$. É a condição neurológica herdada mais diagnosticada no mundo, com incidência é de aproximadamente uma a cada 2500 pessoas, semelhante à da esclerose múltipla ${ }^{2,3}$.

Pertence a um grupo de desordens genéticas, de evolução lenta e progressiva, caracterizado pela degeneração dos nervos motores e sensitivos que levam informação aos membros superiores na parte distal aos cotovelos e aos membros inferiores na parte distal aos joelhos ${ }^{2,4-6}$ com conseqüente diminuição de massa muscular ${ }^{3}$. Pode ser classificada segundo a parte do nervo que é afetada (bainha de mielina ou axônio) 1,2,7,8 e subclassificada de acordo com o gene que a causa ${ }^{2}$. Alguns autores trazem que pessoa que tem problemas com a bainha de mielina é portadora de CMT do tipo I e a pessoa com problemas com o axônio tem o tipo \|\|$^{1,2,7,8}$. Outros são menos radicais e afirmam que o tipo II é caracterizado por menor perda hipertrófica da mielina e maior envolvimento axonal ${ }^{4,6}$. A desmielinização tem uma proliferação secundária de células de Schwann e forma a conhecida "casca de cebola", que aumenta a espessura do nervo periférico. A perda axonal é seguida de degeneração Walleriana ${ }^{1,2,7,8}$.

O tipo II apresenta um comprometimento maior dos músculos da panturrilha e da região anterolateral dos membros inferiores. Por outro lado, há um menor comprometimento dos membros superiores ${ }^{4}$.

A CMT começa geralmente entre 5 e 10 anos3 mas os sintomas podem aparecer na adolescência ${ }^{5}$,ou por volta dos 20 anos de ida$\mathrm{de}^{2,7}$. A fisioterapia, então aparece para manter uma marcha segura e efetiva6, minimizar as manifestações da doença, otimizar a função que os pacientes têm ${ }^{9}$, preservando o arco de movimento e minimizando as deformidades causadas pelo encurtamento ou contratura muscular ${ }^{2,9}$.

O presente estudo que verificou a influência das técnicas fisioterapêuticas no tratamento de um paciente com CMT Tipo II, foi submetido e aprovado pelo Comitê de Ética em Pesquisa da Universidade do Estado de Santa Catarina - CEP/UDESC. Assim, o paciente portador de CMT foi analisado cinesiologicamente antes e depois da intervenção fisioterapêutica; avaliou-se o efeito da mesma sobre o tônus, o equilíbrio e a independência da marcha; e realizou-se uma breve revisão de literatura a respeito do desenvolvimento e tratamento da CMT. O tratamento fisioterapêutico foi descrito detalhadamente e não pode ser comparado, uma vez que se trata de um caso único e percebeu-se certa carência deste tipo de descrição na literatura.

\section{Relato de Caso}

Sujeito do sexo feminino, com 24 anos, contabilista, desempregada, residente em Santo Amaro da Imperatriz, onde mora com os pais. Tem um carro hidramático que é capaz de dirigir. Portadora de CMT do tipo II nega antecedentes familiares. Com 8 anos de idade, teve diagnóstico de ataxia cerebelar com um eletroencefalograma. Aos 11 anos realizou uma eletroneuromiografia que evidenciou "polineuropatia simétrica, axonal, sensitivo-motora, com sinais de desnervação e reinervação em progressão", sinais que podem ser encontrados na CMT tipo II. Ainda com esta idade, realizou cirurgia de liberação da fáscia plantar, para corrigir o pé cavo. Com 16 anos, uma biópsia de nervo sural, diagnosticou "neuropatia crônica desmielinizante com $95 \%$ de imagens em casca de cebola (Charcot Marie Tooth - tipo II)". Após 6 meses, ligou para o médico por só andar com o tornozelo em plantiflexão. Foi, então, orientada pelo médico a forçar o movimento de dorsiflexão até a posição neutra do tornozelo, apesar da queixa álgica ao movimento. Nesta época, não fazia fisioterapia e relata que foi quando mais piorou. Atualmente freqüenta a Clínica Escola de Fisioterapia do Centro de Ciências da Saúde e do Esporte - CEFID e foi selecionada de forma intencional para participar do presente estudo que se caracteriza como estudo de caso. Para realização do mesmo, foi feita uma avaliação contendo dados sobre a identificação e história da doença pregressa e atual da paciente no dia 10/04/2007, e após 32 atendimentos num período de 5 meses e 10 dias, esta foi refeita nos mesmos moldes. Além da ficha de avaliação, foram utilizadas as seguintes escalas:

- Escala modificada de Durigon e Piemonte para avaliação do tônus da paciente ${ }^{10-12}$; - Teste de Berg para avaliar o equilíbrio ${ }^{13,14}$;

- Teste do Tempo de Levantar-se e An- 
dar (Timed Up \& Go Test - TUG) para avaliar a mobilidade funcional e o risco de quedas ${ }^{12,14,15}$.

A escala modificada de Durigon e Piemonte foi criada e validada em 1993 para adultos ${ }^{8}$ e validada em 2004 para crianças com paralisia cerebral ${ }^{11}$. Ela considera 3 aspectos: capacidade de adaptação do fuso muscular ao movimento, intensidade da reação ao alongamento e variação da hipertonia em relação à velocidade do movimento ${ }^{12}$. Testa-se o tônus de certos grupos musculares dos membros inferiores e superiores considerando-se a velocidade e o arco de movimento dos mesmos e um valor de 1 a 10 é atribuído de acordo com a reação ao alongamento. $O$ grau 2 indica normotonia e o grau 1 indica hipotonia. Dos graus 3 ao 10, há um indicativo de hipertonia crescente. Os graus 9 e 10 já apresentam diminuição da amplitude de movimento devido ao aumento do tônus.

A clareza e a validade do teste de Berg foram demonstradas com idosos num estudo publicado em 1992. Além disso, o teste já foi utilizado em estudos sobre distrofia muscular e $\mathrm{CMT}^{13}$. Foi transcrita para o português em 2004 por Miymoto et al. ${ }^{14}$, testada em 36 pacientes idosos e teve sua clareza e validade avaliadas por 40 idosos com mais de 65 anos e 40 terapeutas, respectivamente. O teste consta de 14 itens, descritos na tabela 1, que são tarefas que avaliam equilíbrio estático ou dinâmico. Cada item é pontuado de 0 a 4 e se recebe escore 4 quando se consegue realizar a tarefa. A pontuação máxima é de 56 pontos.

Tabela 1. Itens do Teste de Berg modificados.

\begin{tabular}{|c|c|}
\hline Teste de Berg & Escore total: \\
\hline $\begin{array}{l}\text { 1. Posição sentada para posi- } \\
\text { ção em pé }\end{array}$ & $\begin{array}{l}\text { 8. Alcançar a frente com os } \\
\text { braços estendidos }\end{array}$ \\
\hline $\begin{array}{l}\text { 2. Permanecer em pé sem } \\
\text { apoio }\end{array}$ & 9. Pegar um objeto do chão \\
\hline $\begin{array}{l}\text { 3. Permanecer sentado sem } \\
\text { apoio }\end{array}$ & $\begin{array}{l}\text { 10. Virar-se para olhar para } \\
\text { trás }\end{array}$ \\
\hline $\begin{array}{l}\text { 4. Posição em pé para posi- } \\
\text { ção sentada }\end{array}$ & 11. Girar 360 graus \\
\hline 5. Transferências & $\begin{array}{l}\text { 12. Posicionar pés alterna- } \\
\text { damente no degrau }\end{array}$ \\
\hline $\begin{array}{l}\text { 6. Permanecer em pé com os } \\
\text { olhos fechados }\end{array}$ & $\begin{array}{l}\text { 13. Permanecer em pé com } \\
\text { um pé à frente }\end{array}$ \\
\hline $\begin{array}{l}\text { 7. Permanecer em pé com os } \\
\text { pés juntos }\end{array}$ & $\begin{array}{l}\text { 14. Permanecer em pé sobre } \\
\text { um pé }\end{array}$ \\
\hline
\end{tabular}

Fonte: Miyamoto, $2004^{13}$.

Já o Teste do Tempo de Levantar-se e Andar (Timed Up \& Go Test - TUG) é uma versão modifi- cada do teste original Get up and $\mathrm{Go}^{15}$ e foi criado com o objetivo principal de avaliar o equilíbrio, risco de quedas e capacidade funcional de idosos ${ }^{16}$. Teve sua clareza e validade demonstrada e já foi utilizado em estudo sobre $\mathrm{CMT}^{13}$.

É um teste simples, de rápida aplicação, que consiste na observação do sujeito enquanto este se levanta de uma cadeira, caminha três metros em linha reta, retorna à cadeira e senta-se. $O$ percurso é cronometrado em segundos e o desempenho do sujeito é graduado conforme o tempo despendido: até 10 segundos é o tempo considerado normal para adultos saudáveis, independentes e sem risco de quedas; entre 11 e 20 segundos é o esperado para idosos frágeis ou com deficiências, com independência parcial e com baixo risco de quedas; acima de 20 segundos indica déficit importante da mobilidade física e risco de quedas. Além do tempo, podem ser analisados através de filmagem do mesmo, o giro de $180^{\circ}$, a segurança e o padrão da marcha (simetria, comprimento do passo, balanço dos membros superiores e postura do tronco) ${ }^{16}$.

Após a avaliação, a aplicação das escalas e a filmagem, o tratamento foi feito através de um protocolo de cinesioterapia com ênfase em alongamento e treinamento de equilíbrio. Este programa foi desenvolvido na Clínica Escola de Fisioterapia do Centro de Ciências da Saúde e do Esporte - CEFID - e contou com materiais diversos, como blocos de diferentes alturas para servir como degrau, espaldar e espelho, entre outros. A cada atendimento, foram registrados numa folha simples (sem registro especial) a data, a evolução e o modo como a paciente se sentia.

Os atendimentos se iniciaram com alongamento passivo da musculatura dos membros inferiores que levavam entre 20 e 35 minutos, dependendo da necessidade da paciente. No começo do tratamento, os alongamentos costumavam ser de 25 minutos e no fim do tratamento duravam cerca de 20 minutos. Nos dias mais frios, relatou sentir a musculatura "mais dura", com melhora da sensação após os alongamentos, que foram mais trabalhados.

Ao se aplicar a Escala de Durigon e Piemonte na musculatura dos membros superiores, a mesma se mostrou normotônica. Já a dos membros inferiores apresentou alteração de tônus, sendo que na avaliação, o membro inferior direito apresentou grau 4 para adutores do quadril e extensores do 
joelho e grau 9 para sóleo e gastrocnêmio. Na reavaliação, apenas os extensores do joelho apresentaram diminuição do tônus para grau 3, os demais continuaram com o mesmo grau apresentado no primeiro dia. Já o membro inferior esquerdo, apresentou uma alteração mais significativa, que pode ser visualizada no gráfico 1 . $28^{\circ}$ atendimento, quando chegou a 7 passadas, aumentou-se o degrau para $15 \mathrm{~cm}$ de altura e 2 passadas foram observadas. No último atendimento, dia $18 / 09 / 2007$, a paciente conseguiu 4 passadas sem perder o equilíbrio no mesmo degrau de $15 \mathrm{~cm}$ de altura. Em todos os atendimentos, os exercícios foram supervisionados.

\section{Gráfico 1. Alteração de tônus verificada em membro inferior esquerdo antes e após tratamento fisioterapêutico através da Escala de Durigon e Piemonte modificada.}

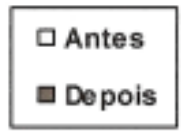

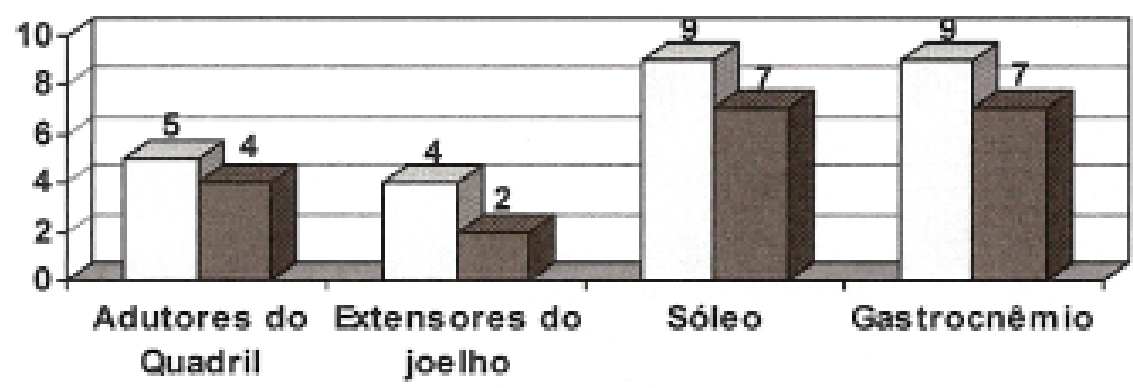

Conforme a paciente apresentava evolução

O grupo muscular que apresentou maior diferença de espasticidade da avaliação para a reavaliação foram os extensores de joelho. Este grupo muscular passou de espástico para normotônico, portanto ficou a dúvida se algum outro fator como dor devida à queda, por exemplo, alterou o resultado do teste na avaliação e não foi considerado. O sóleo e o gastrocnêmio podem ter o resultado do teste melhorado devido a um ganho de ADM passiva.

Em seguida, o treino de equilíbrio estático e dinâmico era realizado de acordo com as tarefas mais difíceis do teste de Berg. Um exemplo é item em que se solicita colocar os pés alternadamente num degrau. No primeiro dia de atendimento, a paciente colocava os pés alternadamente para frente, tendo apenas que atravessar uma linha no chão e conseguia, no máximo, 3 passadas sem perder o equilíbrio. Já no 70 atendimento, conseguia 10 passadas, quando se aumentou a dificuldade. Colocou-se um degrau de 1 centímetro de altura e ela conseguiu 2 passadas. No $16^{\circ}$ atendimento, conseguia 10 passadas e progrediu-se para um degrau de 3 centímetros de altura, onde a mesma conseguiu 4 passadas. No $25^{\circ}$ atendimento, alcançava mais de 10 passadas sem perder o equilíbrio e o degrau passou para 7 centímetros de altura. No na altura do degrau, a mesma relatava menos quedas e sentia melhora da marcha.

Seguindo o mesmo raciocínio, foi realizado treino do item "pegar um objeto no chão", mas neste caso, começou com o objeto num degrau mais alto. No início ela fletiu o tronco sobre o quadril e voltou rapidamente a posição inicial. Durante o treino foi orientada a flexionar o quadril e os joelhos, manter o tronco o mais alinhado possível e aumentar o tempo de execução da tarefa. Com o tempo, passou a realizar o movimento de acordo com o orientado e então a altura do degrau foi diminuindo até que ela se tornou capaz de pegar um objeto no chão. Além disso, o giro de $360^{\circ}$ foi treinado, mas com menos intensidade. Neste item, não houve evolução significativa.

Passando do equilíbrio dinâmico para o estático, pode-se citar o treino do apoio unipodal. No início do tratamento, era incapaz de ficar nesta posição e no fim conseguia manter a posição por 3 segundos. Já no ato de ficar "em pé, com um pé à frente do outro", não se observou evolução e ainda há necessidade de assistência para prevenir a queda nesta posição.

$\mathrm{Na}$ avaliação feita antes do tratamento, a paciente obteve um escore total de 36 no teste de Berg. Já após o tratamento fisioterapêutico, apre 
sentou escore total de 45.

No item número 13 , o escore foi 0 nas duas avaliações. No item 12, apresentou escore um, necessitando de pista verbal na primeira avaliação e de supervisão próxima para a realização da tarefa nas duas avaliações.

Nos itens 1, 2, 3 e 6, obteve escore 4 desde o primeiro dia. No item 8 , também obteve escore 4, mas alcançou $27 \mathrm{~cm}$ no dia 10/05/2007 e $30 \mathrm{~cm}$ no dia 20/09/2007, evidência de evolução positiva. Nos itens 4, 5, 7, 9, 10, 12 e 14, apresentaram evolução mais significativa que pode ser observada no gráfico 2.

Foi realizado, também, treino de marcha no plano, subindo e descendo rampas. No último atendimento, já andava no plano sem auxílio, mas não se sentia segura em grandes distâncias. Necessitava de auxílio nas rampas, entretanto tropeçava menos.
No dia 25/09/2007, após o tratamento fisioterapêutico, a paciente executou o teste em 12,3 segundos e, desta forma, permaneceu no índice do trajeto feito num tempo entre 11 e 20 segundos (mesmo da avaliação). Entretanto não precisou de supervisão próxima para realizar o teste, a antepulsão do tronco foi menor e o movimento de pêndulo foi menor. Além disso, o paciente já conseguiu desencostar os artelhos do chão na fase de balanço na maioria dos passos. Não fez a pausa antes do giro manteve a velocidade da marcha. Ao sentar, controlou melhor a descida, desta vez, sem apoiar as mãos. Quanto ao padrão de marcha, percebeu-se que a paciente passou a ter um tempo mais longo de balanço, arrastando menos os artelhos no chão. Pode-se atribuir a esta melhora, a diminuição no número de quedas que a mesma apresenta (SIC).

\section{Gráfico 2. Alteração de equilibrio verificada antes e após a intervenção fisioterapêutica} através do Teste de Berg.

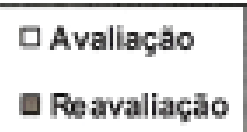

Na avaliação do dia 10/05/2007, a paciente se sentiu cansada e pediu para adiar a realização do teste do Tempo de Levantar-se e Andar. Então ele foi feito no dia 15/05/1007 e executado em 14,2 segundos, com supervisão próxima. Levantou da cadeira sem se apoiar nos braços, e iniciou a marcha. Houve uma antepulsão do tronco e ela se movimentou fazendo um pêndulo látero-lateral com o corpo. Arrastou os artelhos no chão na fase de balanço durante todo o trajeto e os membros superiores ficaram levemente abduzidos. Fez uma pausa antes de realizar a virada, flexionou os cotovelos e cerrou as mãos. Girou $180^{\circ}$ de forma lenta quando comparada à velocidade da marcha e voltou com o mesmo padrão de marcha. Sentou sem segurar no braço da cadeira, mas controlou a descida com as mãos nos joelhos.
Sabe-se que a análise qualitativa do TUG tem algumas limitações como a condição climática, pois na avaliação pré, o dia estava frio e chuvoso e a paciente estava com um casaco pesado enquanto na pós, estava mais calor e a paciente usava apenas uma blusa. Este fator pode ter influenciado no resultado do teste, no entanto não temos como mensurar o quanto. Outros fatores como iluminação, barulho e local da coleta foram mantidos a fim de evitar interferência.

\section{DISCUSSÃO}

Assim que o diagnóstico da CMT é feito, o fisioterapeuta faz uma avaliação. Os planos formulados com o resultado do exame devem objetivar o desenvolvimento de todo o potencial do paciente. 
Assim, é muito importante que haja uma avaliação contínua, de modo a manter um registro de qualquer alteração que possa indicar progressão ou regressão ${ }^{17}$. Neste estudo não foi possível realizar a avaliação após o diagnóstico. Porém, durante o tratamento a avaliação foi contínua como recomenda a literatura.

Não existe atualmente cura para a $\mathrm{CMT}^{2,18}$, mas a fisioterapia e a terapia ocupacional são uma parte importante do tratamento ${ }^{2}$, que deve basear-se primariamente na manutenção da função, como foi feito neste estudo, já que não se conhece nenhuma forma de alterar a progressão da doença $a^{7,17,19}$. O foco da reabilitação deve ser manter uma marcha segura e efetiva ${ }^{6}$, minimizar as manifestações da doença, otimizar a função que os pacientes têm ${ }^{9}$, preservando o arco de movimento e minimizando as deformidades causadas pelo encurtamento ou contratura muscular, ${ }^{2,9}$.

A severidade dos sintomas da CMT pode variar muito, mesmo em indivíduos de uma mesma família ${ }^{2,5}$. Há progressiva atrofia muscular que resulta em fraqueza severa dos punhos, mãos e dedos, dos pés, tornozelos e da parte distal das pernas ${ }^{1,2,4-6,20}$. No caso estudado, observou-se fraqueza significativa dos membros inferiores, com preservação dos membros superiores. É possível haver diminuição da função sensorial tátil ou dolorosa em forma de luva ou meia, diminuição da propriocepção das articulações mais distais ou ainda diminuição da propriocepção ${ }^{20}$. Essa diminuição geralmente é moderada e não acontece na metade dos casos, inclusive neste.

O desconforto muscular, as contraturas e as fasciculações são pouco freqüentes, mas reclamações de frio nas pernas e cãibras são comuns, principalmente após exercício ${ }^{2,3}$. A paciente em questão não apresentou estes problemas. A função intelectual e o perfil neuropsicológico do portador de CMT é normal ${ }^{3,6}$, o que se confirmou neste indivíduo.

A espasticidade, caracterizada como um aumento do tônus dependente da velocidade ${ }^{21}$, não parece ser fator determinante de deformidade nos pacientes com CMT, pois em um estudo realizado com 61 pacientes de 18 famílias e nenhum deles apresentou espasticidade ${ }^{22}$. Neste caso, entretanto, percebeu-se espasticidade em graus variados nos membros inferiores, conforme se apresenta no gráfico 1.

Esta espasticidade pode ser justificada pelo comprometimento do neurônio motor superior ou como alteração que pode ser encontrada em alguns pacientes com $\mathrm{CMT}^{20}$. As técnicas utilizadas tradicionalmente no tratamento da espasticidade incluem um direcionamento funcional com ênfase no fortalecimento, exercícios para aumentar a resistência muscular, várias técnicas de neurofacilitação ${ }^{23}$, posicionamentos, mobilização articular passiva, posturas e estiramentos feitos para evitar a instalação de complicações ${ }^{24}$.

Em um estudo em que dez indivíduos com espasticidade após acidente vascular cerebral utilizaram, em suas casas, um equipamento controlado por feedback que fazia o alongamento passivo dos planti e dorsiflexores, três vezes por semana, por 45 minutos durante quatro semanas observou-se que $o$ alongamento teve uma influência positiva na musculatura envolvida e o aparelho pode ser uma alternativa ao alongamento passivo manual realizado pelo terapeuta ${ }^{25}$. Neste estudo, realizouse alongamento passivo manual com auxílio do terapeuta e o membro inferior esquerdo teve uma diminuição mais significativa da espasticidade do que o membro inferior direito. Além disso, o grupo muscular que apresentou maior diferença de espasticidade, ao se comparar a primeira avaliação com a final, foram os extensores de joelho (gráfico 1). Isso foi confirmado com a melhora do padrão da marcha, em que se percebe melhor flexão de quadril e joelho. A atrofia muscular provavelmente começa nos músculos intrínsecos do pé e sobe para o peroneal, o tibial anterior, o extensor do hálux e o tríceps sural. Às vezes a parte distal do vasto medial ou outros músculos do quadríceps também se tornam atrofiados e se a gordura subcutânea não for abundante, a perna terá o aspecto de uma garrafa de champagne invertida ou "pernas de cegonha", o que não se verifica nesta paciente.

De qualquer forma, a atrofia muscular distal dos membros inferiores é sempre a mais pronunciada ${ }^{20}$, o que pode ser visualizado neste caso.

Como nesteestudo, acompanhando a atrofia, vem a fraqueza muscular que é simétrica e freqüentemente resulta na deformidade dos pés observada neste estudo e caracterizada pela convexidade excessiva do dorso com elevação do arco plantar e presença de dedos em martelo ${ }^{20}$. Tanto fraqueza da musculatura distal dos membros inferiores quanto a deformidade podem e dificultam seriamente a vida da participante desta pesquisa e dos demais portadores de CMT. Permanecer na posição ortostática se torna difícil e a marcha pode ser atrasada 
pela incapacidade de levantar o antepée, $3,5,7,20$.

A elevação pélvica no lado que está na fase do balanço passou a ser usada para compensar o pé caído ${ }^{20}$ e percebeu-se que o sujeito em estudo ainda fazia um movimento de pêndulo invertido para os lados, na tentativa de aumentar essa elevação (movimento que diminuiu após o tratamento). Por isso a marcha se tornou, tanto para ela quanto para os pacientes relatados pela literatura, algo extremamente cansativo e hoje se resume a curtas distâncias. Caminhar numa superfície irregular é muito difícil e, em casos mais avançados, a dificuldade é tão grande que os indivíduos passam a arrastar os pés. Muitos tropeçam nas menores irregularidade ${ }^{20}$ e a paciente cita que tapetes e às vezes um nivelamento mal feito do chão são motivos para as quedas que se tornaram algo comum na sua vida ${ }^{6}$.

O indivíduo tende aumentar a velocidade da marcha e torcer os tornozelos ${ }^{2,4}$. Isso era visível no início do tratamento. Após o tratamento, há controle da velocidade da marcha com comando verbal do terapeuta, mas os tornozelos ainda torcem. Indivíduos acometidos por CMT não são capazes de correr, a paciente deste trabalho relata que já não corre desde os nove anos de idade ${ }^{5}$.

O equilíbrio estático também se apresenta deficitário e o sujeito em estudo faz outro movimento de pêndulo invertido quando se encontra na posição ortostática, desta vez para frente e para trás. Este movimento ocorre mesmo com os olhos abertos, e, isto sugere que a visão não compensa completamente o déficit sensorial ${ }^{26}$.

O autor diz que o equilíbrio dinâmico é menos afetado que o estático, mas neste caso, os dois tipos de equilíbrio foram afetados, como demonstra o gráfico 2.

O treino de equilíbrio estático e dinâmico foi realizado enfatizando as tarefas com a menor pontuação no teste de Berg (gráfico 2). Como em outro estudo onde as mudanças no escore do teste depois do tratamento foram relativamente pequenas, mas isso é devido a natureza da patologia, em que uma pequena melhora funcional é observada após fisioterapia intensiva ${ }^{13}$.

Entretanto, essas pequenas mudanças podem ser clinicamente importantes para os pacien tes com CMT, pois qualquer progresso no seu equilíbrio ou padrão de marcha é benéfico, diminuindo a incidência de quedas durante suas atividades. Os registros da evolução deste caso concordam com essa diminuição e trazem que no começo do tratamento, havia pelo menos uma queda toda semana e nos últimos 3 meses, não houve quedas.

Em estudo com 16 portadores de CMT que foram divididos em um grupo experimental e um grupo controle, os atendimentos consistiam em alongamento passivo, fortalecimento muscular e treino do equilíbrio dinâmico ${ }^{13}$. O grupo experimental utilizou um equipamento mecânico comercialmente disponível para treino de equilíbrio enquanto os pacientes do grupo controle eram fisicamente tratados por um fisioterapeuta. A intervenção foi feita por 12 dias. $O$ equilíbrio e as funções de mobilidade foram testados antes e depois da intervenção através do teste de Berg, do TUG e do teste de caminhada de dez metros. As razões possíveis para a melhora que se observou no equilíbrio e na mobilidade dos dois grupos que praticaram treino do equilíbrio dinâmico, bem como na paciente deste estudo, pode ser ligada aos efeitos do treino que melhorou a utilização de equilíbrio compensatório e estratégias de movimentos da musculatura proximal dos membros inferiores que é requisitada quando há fraqueza da musculatura distal.

\section{CONSIDERAÇÕES FNAIS}

A análise feita com os dados desse estudo revelou melhora no equilíbrio estático e dinâmico, no padrão e na independência da marcha após a intervenção fisioterapêutica, como o encontrado nos estudos supracitados. Houve uma diminuição da espasticidade após os alongamentos realizados durante o tratamento, que foi verificada através da aplicação da escala de Durigon e Piemonte modificada.

O treino de equilíbrio estático e dinâmico mostrou-se eficiente através da análise do Teste de Berg antes e depois da fisioterapia. Além disso, este treino tornou a paciente apta a elevar mais o joelho na fase de balanço da marcha.

Com isso, diminuiu a elevação do quadril e já faz o movimento de pêndulo látero-lateral em menor amplitude, como se viu na filmagem feita noTUG.

O TUG também revela melhora na mobilidade funcional da paciente. Isso se confirma ao se perceber que o maior benefício do tratamento foi o fato de ela não arrastar mais os artelhos no chão, o que diminuiu muito a incidência das que 
das (sic). A partir destes achados, fica evidente que houve melhoras, mas abre-se a dúvida de o quanto essas melhoras atingem a funcionalidade e a qualidade de vida desses pacientes e sugere-se a realização de novos estudos que venham a analisar estes fatores.

Para evitar que a avaliação ficasse muito longa para a paciente e, desta forma, desconfortável, foram escolhidos apenas alguns testes.

\section{REFERÊNCIAS}

1.Birouk N, Gouider R, Guern EL, Gugenheim M, Tardieu S, Maisonosobe $\mathrm{T}$, et al. Charcot-Marie-Tooth disease type $1 \mathrm{~A}$ with 17p11.2 duplication : Clinical and electrophysiological phenotype study and factors influencing disease severity in 119 cases. Brain 1997;120:813-23.

2.Longe JL, Blanchfield DS. The Gale Encyclopedia of Medicine. 2. ed. Farmington Hills: Gale Group, 2002, 3500p.

3.Campbell RJ. Psychiatric Dictionary. 7 ed. New York: Oxford University Press, 1996, 701p.

4.Sanvito WL. Síndromes neurológicas. 2. ed. São Paulo: Atheneu, 1997, 599p.

5.Wynbrandt J, Ludman MD. The Encyclopedia of Genetic Disorders and Brith Defects. 2. ed. New York: Facts on File Inc, $1999,682 p$

6.Delisa JA. Physical Medicine and Rehabilitation: Principles and Practice. 4 ed. Philadelphia: Lippincott Williams \& Wilkins, 2005, 1926p.

7.Braddom RL. Physical Medicine \& Rehabilitation. Philadelphia: WB Sauders Company, 1996, 1301p.

8.Sevilla T, Cuesta A, Chumillas MJ, Mayordomo F, Pedrola L, Palau F, et al. Clinical, electrophysiological and morphological findings of Charcot-Marie-Tooth neuropathy with vocal cord palsy and mutations in the GDAP1 gene. Brain 2003;126:202333.

9.Oatis CA Conservative Management of the Functional Manifestations of Charcot-Marie-Tooth Disease. In: Lovelace RE, Shapiro HK. Charcot-Marie-Tooth Disorders: Pathophysiology, Molecular Genetics and Therapy. New York: Alan R. Liss Inc, 1990, 448p.

10.Durigon OFS, Piemonte MEP. Desenvolvimento de Protocolo para Avaliação do Tono Muscular. In: Anais do Congresso Brasileiro de Fisioterapia e Congresso Paulista de Fisioterapia, São Paulo: ABF, 1993, p.31.

11.Durigon OFS, Sá CSS, Sitta LV. Validação de um protocolo de avaliação do tono muscular e atividades funcionais para crianças com paralisia cerebral. Rev Neurocienc 2004;12:8793.

12.Iwabe C, Piovesana AMSG. Estudo comparativo do tono muscular na paralisia cerebral tetraparética em crianças com lesões predominantemente corticais ou subcorticais na tomografia computadorizada de crânio. Arq Neuropsiquiatr 2003;61:617-20.
Não foi testada, por exemplo, a força muscular. No entanto, considera-se de grande importância a sua avaliação nos próximos estudos, uma vez que a fraqueza é um sintoma direto da doença. Outros fatores que poderiam ser explorados em novas pesquisas são as coordenações motoras fina e global, o esquema corporal e a sensibilidade, que afetam a marcha e a funcionalidade do indivíduo e, portanto, devem ser consideradas.

13.Matjacic Z, Zupan A. Effects of dynamic balance training during standing and stepping in patients with hereditary sensory motor neuropathy. Disabil Rehab 2006;28:1455-9.

14.Miyamoto ST, Lombardi Junior I, Berg KO, Ramos LR, Natour J. Brazilian version of the Berg balance scale. Brazilian version of the Berg balance scale. Braz J Med Biol Res 2004;37:1411-21. 15.Mathias S, Nayak U, Isaacs B. Balance in the elderly patient: The "Get-up and Go" test. Arc Phys Med Rehab 1986;67:387-9. 16.Podsiadlo D, Richardson S. The Timed "Up \& Go": a test of basic functional mobility for frail elderly persons. JAGS 1991;39:142-8.

17.Thomson A, Skinner A, Piercy J. Fisioterapia de Tidy. São Paulo: Editora Santos, 1994, 500p.

18.Klag MJ. Johns Hopkins Family Health Book. New York: Harper Collins Publishers, 1999, 1680p.

19.Vinci P, Perelli SL. Footdrop, Foot Rotation, and Plantarflexor Failure in Charcot-Marie-Tooth Disease. Arch Phys Med Rehabil 2002;83:513-6.

20.Vinken PJ, Bruyn GW, Klawans HL. Handbook of Clinical Neurology. Amsterdam: Elsevier Science Publishers, 1991, 669p.

21.Lee HM, Chen JJJ, Ju MS, Lin CCK, Poon PPW. Validation of portable muscle tone measurement device for quantifying velocity-dependent properties in elbow spasticity. J Electromyograph Kinesiol 2004;14:577-89.

22.Bienfait HME, Baas F, Koelman JHTM, De Haan RJ, Van Eengelen BGM, Gabreëls-Festen AAWM, et al. Phenotype of Charcot-Marie-Tooth disease Type 2. Neurology 2007;68:1658-67. 23. Hesse S, Jahnke MT, Schaffrin A, Lucke D, Reiter F, Konrad M. Immediate effects of therapeutic facilitation on the gait of hemiparetic patients as compared with walking with and without a cane. Electroencephalograph Clin Neurophysiol 1998;109:515-22.

24.Veiros I, Martins L, Martins F. Baclofeno intratecal no tratamento da espasticidade. Acta Med Port 2006;19:217-24.

25.Selles RW, Li X, Lin F, Chung SG, Roth EJ, Zhang LQ. Feedback-Controlled and Programmed Stretching of the Ankle Plantarflexors and Dorsiflexors in Stroke: Effects of a 4-Week Intervention Program. Arc Phys Med Rehab 2005;86:2330-6.

26.Nardone A, Grasso M, Schieppati M. Balance control in peripheral neuropathy: Are patients equally unstable under static and dynamic conditions? Gait Post 2006;23:364-73. 